\title{
Phonemic and category encoding of unattended words in dichotic listening
}

\author{
ELIZABETH TRAUB and GINA GEFFEN \\ School of Social Sciences, Flinders University of South Australia \\ Bedford Park, Bedford 5042, Australia
}

\begin{abstract}
The claim that unattended items in dichotic listening are categorized (Smith \& Groen, 1974) was examined in three experiments using dichotic presentation and probe reaction time. Negative probe words from the unattended list were more difficult to reject when the dichotic lists shared a semantic category than when they differed in category, whether or not the attended list was precued, thereby replicating and extending Smith and Groen's findings. The difficulty with intralist probes following dichotic lists of a homogeneous category was found to be a special case of the probe similarity effect, since extralist probes of the same category as the attended input were rejected more slowly (and with more errors) than different category probes. The effects of category homogeneity were evident on the attended, but not on the unattended, inputs (Experiment 2). The third experiment compared focused and divided attention with dichotic lists of unrelated items. Phonemically similar probes were more difficult to reject when related to items on the attended channel in the focused condition than either channel in divided attention, and easiest to reject when similar to an unattended item. Linear regression confirmed that the unattended input was processed only at a precategorical (acoustic) level.
\end{abstract}

The level of processing of unattended words in dichotic listening has been extensively investigated to test theories of attention proposing selection of inputs at a preperceptual vs. postperceptual level. Postperceptual selection has been suggested by studies that investigated the effect of unattended material on response to the attended message. Unattended words can bias the interpretation of an ambiguous attended message (Lackner \& Garrett, 1973), as can subliminal cue words for homophones presented at supraliminal intensities (Henley, 1976). Effects attributable to the semantic processing of unattended items are, however, not always facilitatory. When subjects were asked to decide if a probe word was an item on an attended list, correct rejection of a negative probe that had been an item on the unattended list was more difficult when the dichotically presented lists consisted of words from the same category rather than when the lists differed in category (Smith \& Groen, 1974).

Posner and Snyder (1975) suggest that semantic analysis occurs with the automatic activation of semantic pathways, resulting in a similar build-up of semantic information for both attended and unattended verbal material. However, when dichotic lists were from the same semantic category, processing of unattended

This research was supported by a grant to Gina Geffen from the Australian Research Grant Committee. We are grateful to M. Smith for comments on an earlier draft of this paper, and to Paul Tildesley for computing associated with dichotic tape preparation. Reprint requests should be sent to G. Geffen, School of Social Sciences, Flinders University of South Australia, Bedford Park 5042, Australia. words could have been due to semantic facilitation by attended words. Semantic facilitation has been found between related dichotic words in divided attention (Kadesh, Riese, \& Anisfeld, 1976).

A number of findings do not support postperceptual selection. Context on either the attended or unattended dichotic message decreases shadowing latencies; however, the amount of context shows an increment in facilitation only when it is on the attended input (Underwood, 1977). Interference in shadowing has been shown with synonyms of attended words presented on the unattended ear (Lewis, 1970), but this occurs only at early list positions when attention has not been fully oriented (Treisman, Squire, \& Green, 1974). With simultaneous presentations of dichotic inputs, words interfered in attended recall no more than nonsense syllables, whereas staggered unattended words were more interfering (Davis \& Smith, 1972). Semantic facilitation may lead to the perception of unattended printed words semantically related to attended words (Underwood, 1976). However, the degree of facilitation is greater when both sets of words are attended to (Dallas \& Merikle, 1976).

When stimulus locations (e.g., the to-be-attended input) are clear, the presence of an irrelevant stimulus need not produce a deficit in relevant processing (Shiffrin \& Schneider, 1977) or in the memory for attended items (Davis \& Smith, 1972). Providing an auditory cue (e.g., four digits) prior to list presentation increases perceptual selection by source (Treisman et al., 1974). With only a single tap on the attended ear prior to list onset, Smith and Groen (1974) may not have 
provided an adequate cue. Semantic processing of unattended words may, therefore, have been due to some sampling of unattended items, as found by Smith and Burrows (1974).

The following studies investigated response difficulty to various probes (1) in a replication of Smith and Groen's (1974) study when the attended list was randomly cued (Experiment 1), (2) with varied homogeneity of category on the attended and unattended lists (Experiment 2), and (3) related semantically or phonemically to list items in the absence of a definable category (Experiment 3).

\section{EXPERIMENT 1}

This experiment partially replicated the Smith and Groen (1974) study that had only five subjects. The subject's task was to respond positively if the probe word had occurred on the attended channel and negatively if it had not. Negative probes could be intralist (from the unattended channel) or extralist (had not occurred on either channel). The Smith and Groen effect was that intralist probes were more difficult to reject when the attended and unattended lists shared the same category than when they were of different categories.

Measurement of a semantic effect of the unattended input may be influenced by the rather short memory span for unattended material (Glucksberg \& Cowen, 1970; Klapp \& Lee, 1974; Treisman, 1964). Unattended verbal memory appears to decay rather than to be displaced by subsequent verbal input (Bryden, 1971). Therefore, maximum response difficulty should be found when dichotic lists are presented within about $4 \mathrm{sec}$.

A faster rate of stimulus presentation than the $1 \mathrm{pair} / \mathrm{sec}$ used by Smith and Groen (1974) may influence the efficiency of categorization. However, assuming that both input channels are semantically analyzed, any effect of rate should occur for both attended and unattended words. An indication of processing efficiency for the attended list would be shown by a category effect on probe decisions. Extralist probes should be more difficult to reject when they share the same category of the positive set than when they differ in category (Lively \& Sanford, 1972; Smith \& Groen, 1974).

In the present experiment, digits were used to initiate half of the lists. It was predicted that with cued lists there would be shorter latencies and fewer errors in response to probes that had been unattended items.

\footnotetext{
Method

Subjects. The subjects were eight right-handed male volunteers from an introductory psychology class. No subject had known hearing defects.

Apparatus. Stimulus tapes were prepared with a Sony TC-854 four-channel tape recorder. Trial segments were marked by recording onto one channel $50-\mathrm{msec}$ tones of $1 \mathrm{kHz}$, computer
}

generated at $10-\mathrm{sec}$ intervals. Paced by $.5-\mathrm{sec}$ tones, dichotic word lists were recorded separately onto two other channels at a rate of 1 word pair $/ 500 \mathrm{msec}$. The last word pair for each trial was enunciated before the corresponding single tone. Word asynchrony was less than $80 \mathrm{msec}$, with neither channel consistently leading. Half of the dichotic lists (randomly determined within four blocks) were preceded by 5 random digits (excluding the digit 7) that were recorded onto the fourth channel at 2 digits/sec. Probe words were recorded simultaneously onto both word-list channels $1 \mathrm{sec}$ after the single (end-oflist) tone for each trial. Digits, word lists, and probe words were recorded in the same male voice.

Channel outputs were presented to the subject over Akai ASE-95 matched stereo headphones at an intensity of $60 \mathrm{~dB}$. The channel containing the digits was mixed via a Revox A-77 tape recorder with the word list to be attended. The end-of-list tones were mixed with both word-list channels and were on-line to a PDP $11 / 10$ computer. Precise measurement of the interval from the tone to the initiation of each probe word was measured preexperimentally by computer. This interval for each probe word was subtracted from the experimental response latency measured from the tone to depression of one of two keys on a response panel. On-line response latencies and accuracy rates were obtained per probe type and experimental condition.

Stimulus materials. Word lists of six mono- or bisyllabic nouns were constructed from category norms (Battig \& Montague, 1969). Within any list, the words were representative of only one semantic category. Lists were paired with a different list of words from the same category (AA lists) or with a list from a different category (AB lists). There were 144 pairs of lists for each combination, sampling 44 categories in all. Half of the pairs within each list type were randomly designated to be initiated by a digit sequence, providing that categories were represented equally often with and without list initiation. Each list word was used twice, only once on an attended list, and the repetition was not probed.

Half of all probe words for $\mathrm{AA}$ and $\mathrm{AB}$ lists with and without prelists were positive, being items drawn from the attended ists. Negative probe words were either of the same category as the attended list or of a different category. Intralist probes (items drawn from the unattended lists) were of the same category as attended words with AA lists, and of a different category with $A B$ lists. Extralist probes (items that had not occurred on either list following both $\mathrm{AA}$ and $\mathrm{AB}$ lists) were either of the same category as the attended list or of a category different from both dichotic lists. Examples of lists and probe words are given in Table 1 . There were 12 trials per negative probe type in each list-combination/prelist condition. Positive and negative intralist probes were drawn equally of ten from Serial Positions 1,3 , and 6.

Procedure. Output volumes were equated by each subject, with dichotic prose recorded at the same volume as word lists. Practice trials sampling all probes were given. No subject failed to reach a criterion of $16 / 24$ correct responses in a single practice session.

The experimental session consisted of four blocks of trials, with probe types and list conditions equally represented in different randomizations within each block. The order of blocks were counterbalanced in a Latin square design over subjects. Four subjects attended to the right ear, and the others to the left ear for the whole session. Responses were made with the index or middle fingers of the hand ipsilateral to the attended ear, and the fingers for positive and negative responses were also counterbalanced between subjects.

To minimize eye movements during list presentation, subjects fixated a red spot affixed between the keys of the response panel. Subjects were asked to respond "yes" if the probe word had occurred on the list presented to the attended ear, otherwise, "no," by depression of the appropriately labeled response key. Speed and accuracy were given equal emphasis. 
Table 1

Examples of Various Probe Words of the Same Category as the Attended List or of a Different Category

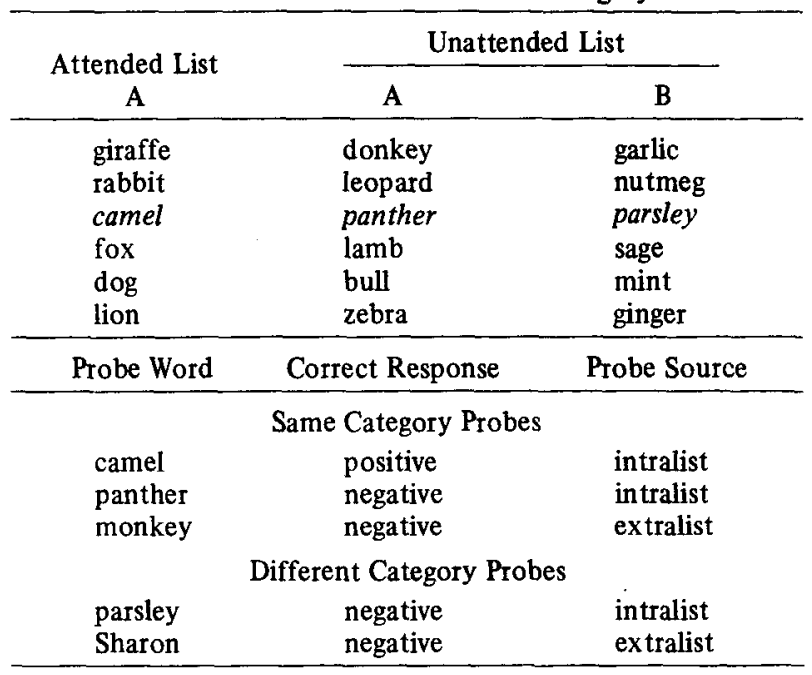

Note-AA combinations paired attended and unattended lists of the same category; $A B$ combinations paired lists of different categories.

The response panel, labels, and headphones were reversed for the last two trial blocks. Subjects were informed that some trials would be initiated by digits on the ear to be attended, but that these would never be tested. The input to the unattended ear was identified as a distractor, and subjects were informed that they would achieve better performance by ignoring it. Rest periods were given after each of the trial blocks, and the session lasted about $60 \mathrm{~min}$.

\section{Results and Discussion}

Analysis of variance on mean correct reaction times (RTs) and mean error rates for positive probes showed no significant effects or interaction of list pairing and list cuing $[F(1,7)<1]$. Of particular note is the absence of a prefixation effect attributable to the cuing of lists with irrelevant verbal stimuli. Without list cuing, the mean positive RT was $876 \mathrm{msec}$, with a $12.5 \%$ error rate, whereas following cued lists, the mean positive RT was $851 \mathrm{msec}$ with $11.4 \%$ errors. As found by Smith and Groen (1974), positive probe responses were faster and more accurate only when the probe word has been the last item on the attended list.

Mean correct RTs and error rates for negative probes are shown in Figure 1. An analysis of variance on errors with the factors of cue (two), lists (two), and probe type (three) showed that more errors were made with cued than uncued lists $[F(1,7)=7.30, p<.05]$, with intralist than either of the extralist probes $[F(2,14)=16.49$, $\mathrm{p}<.001]$, and with same category (AA) than different category $(A B)$ lists $[F(1,7)=18.45, p<.01]$. The Lists by Probe Type interaction showed that error rates were higher for intralist probes of $\mathrm{AA}$ than $\mathrm{AB}$ lists, whereas extralist probe error rates did not differ between lists $[F(2,14)=12.44, p<.001]$. List cuing increased errors on $\mathrm{AA}$ but not $\mathrm{AB}$ lists; this Cue by List interaction was significant $[F(1,7)=6.98, p<.05]$. Although the effect of cuing was stronger for the ex tralist than intralist probes of AA lists (see Figure 1), the threeway interaction was not significant $[\mathrm{F}(2,14)=3.26$, $p>.05]$. Error rates for intralist probes were similar for the three serial positions probed with either list pairing.

An analysis of mean correct $R T$ s for negative probes showed that response was slower following same (AA) rather than different $(\mathrm{AB})$ category lists $[\mathrm{F}(1,7)=8.73$, $\mathrm{p}<.05]$. RT for intralist probes (mean $=993 \mathrm{msec}$ ) was slower than for extralist different category probes (mean $=914 \mathrm{msec}$ ) $[\mathrm{F}(2,14)=5.58, \mathrm{p}<.05]$. The interaction of Lists by Probe Type was significant $[F(2,14)=7.53, p<.01]$. Comparisons showed that faster responses occurred for intralist (different category) probes following $\mathrm{AB}$ lists than intralist (same category) probes of AA lists [1.s.d.(14) $=159 \mathrm{msec}$, $\mathrm{p}<.01]$. Extralist different category probes received faster responses following $\mathrm{AB}$ than $\mathrm{AA}$ lists; however, the RT for extralist same category probes did not differ with list pairing. The interaction of Cue by Probe Type was also significant $[F(2,14)=5.76, p<.05]$. The effect of list cuing on RT was shown with extralist rather than intralist probes. Responses to extralist same category probes were significantly longer than for extralist different category probes only when the lists were cued [1.s.d.(14) $=145 \mathrm{msec}, \mathrm{p}<.01$ ], indicating that a category effect on response was dependent on list cuing. The cuing digits may have primed category recognition, since subjects had to recognize when the digit string ended and the word list began. However, this effect was clearly limited to the facilitation of attended rather than unattended processing. The three-

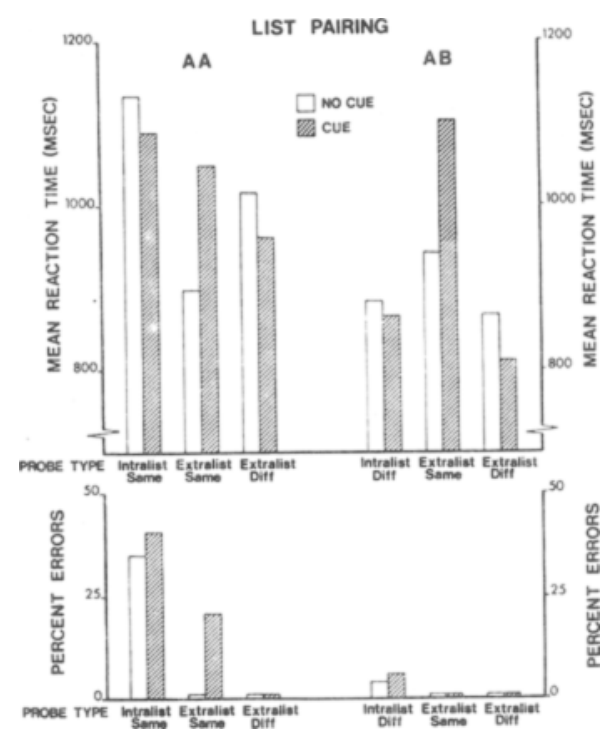

Figure 1. Mean correct RTs and error rates for negative probes following same (AA) and different (AB) category lists with and without list cuing. 
way interaction was not significant $[F(2,14)<1]$.

It was predicted that emphasizing perceptual selection by ear with an auditory cue would decrease response difficulty for probes that had been unattended items. The main finding of Smith and Groen (1974), however, was replicated in both the cued and uncued conditions. More response difficulty with intralist probes of same rather than different category lists was, therefore, not due to inadequate selection of dichotic inputs. The highest error rates were found for intralist (unattended) probes that matched the attended list category. This could be due to the combined effects of (1) matching the attended list category and (2) having a phonological representation in memory. A further test of semantic processing of unattended words was carried out in Experiment 2, which varied the homogeneity of the categories on the dichotic lists.

\section{EXPERIMENT 2}

Experiment 1 showed that probes that matched the category of the attended list caused more response difficulty than probes that did not. Between-categories discrimination could occur when the probe word was of a different category from the positive set. However, when there is a category match of the probe word to the positive set, correct responses to both positive and negative intralist probes must be determined by item rather than category features (i.e., within-categories discrimination). The number of exemplars encoded for a positive set category increased search time (Naus, 1974) and would be expected to influence withincategories discrimination. Furthermore, the number of categories (in excess of two categories) encoded during list presentation increased RT to category labels (Smith \& Abel, 1973) and should therefore have made betweencategories discrimination more difficult.

If unattended words are semantically processed (categorized) independently of the level of processing of the attended list, then semantic activation by the unattended items should produce a representation in memory of these categories. The effect of unattended words on within- and between-categories discrimination was investigated by presenting dichotic lists in which the category homogeneity was systematically varied (see Table 2). The attended list was either homogeneous (A) or mixed (X) in category. The unattended list could either match the attended list (AA, XX combinations) or not (AX, XA combinations). If unattended items are semantically processed, then responses to intralist probes (see Table 2) should be slower and errors more frequent when the unattended list is homogeneous rather than mixed (AA vs. AX, and XA vs. XX). This tested within-categories discrimination. Extralist probes of a different category from either list would test between-categories discrimination. Responses to the different category probes (extralist) should be slower (with more errors) when the unattended list contains
Table 2

Examples of Intralist and Extralist Probe Words for Attended and Unattended Homogeneous (A) and Mixed (X) Category Lists

\begin{tabular}{|c|c|c|c|}
\hline \multicolumn{2}{|c|}{ Attended } & \multicolumn{2}{|c|}{ Unattended } \\
\hline A & $\mathrm{X}$ & $\mathbf{A}$ & $\mathrm{X}$ \\
\hline $\begin{array}{l}\text { giraffe } \\
\text { rabbit } \\
\text { camel } \\
\text { fox } \\
\text { dog } \\
\text { lion }\end{array}$ & $\begin{array}{l}\text { finger } \\
\text { dentist } \\
\text { camel } \\
\text { tea } \\
\text { dove } \\
\text { window }\end{array}$ & $\begin{array}{l}\text { donkey } \\
\text { leopard } \\
\text { panther } \\
\text { lamb } \\
\text { bull } \\
\text { zebra }\end{array}$ & $\begin{array}{l}\text { artist } \\
\text { kitchen } \\
\text { monkey } \\
\text { couch } \\
\text { verb } \\
\text { typhoon }\end{array}$ \\
\hline Probe Word & \multicolumn{2}{|c|}{ Correct Response } & Probe Source \\
\hline $\begin{array}{l}\text { camel } \\
\text { panther } \\
\text { monkey } \\
\text { Sharon }\end{array}$ & \multicolumn{2}{|c|}{$\begin{array}{l}\text { positive } \\
\text { negative } \\
\text { negative } \\
\text { negative }\end{array}$} & $\begin{array}{l}\text { intralist } \\
\text { intralist } \\
\text { intralist } \\
\text { extralist }\end{array}$ \\
\hline
\end{tabular}

Note-Attended $A$ list paired with unattended $A$ or $X$ lists gives $A A$ or $A X$ combinations; attended $X$ list paired with unattended $A$ or $X$ lists gives $X A$ or $X X$ combinations.

more categories ( $\mathrm{AX}, \mathrm{XX}>\mathrm{AA}, \mathrm{XA})$, if indeed these categories are encoded.

\section{Method}

Subjects. All 24 subjects were right-handed undergraduates enrolled in introductory psychology courses, none of whom had participated in Experiment 1 or had known hearing defects. Subjects were randomly assigned to one of two experimental groups.

Apparatus. The experimental arrangement and tape preparation was the same as for Experiment 1, with the exœeption that all word lists were preceded by five random digits on the attended ear.

Stimulus materials. Lists of six words were constructed from the pool of words used in Experiment 1. Half of the lists were designated as attended lists, of which 80 lists consisted of words from only one category, and 80 were made up of words from different categories. Homogeneous attended lists were paired with either (1) a different list of words from the same category as the attended list (AA lists), or (2) a list of different category words with only one word from the attended list category (AX). Mixed category attended lists were similarly paired either with (1) a list of words, all of the same category as one attended word (XA), or (2) a mixed category list, of which only one word was the same category as one attended word (XX).

List combinations and examples of probe words are illustrated in Table 2. Half of all probe words were positive (items that had occurred on the attended list). Negative probe words were either intralist or extralist. Intralist probes were items drawn from unattended lists and were of the same category as the accompanying attended list word at the same serial position $(1,3$, or 6$)$. Extralist probes were of a different category from any item presented on either dichotic list. No probe words were repeated. Extralist same category probes (testing the effect of an acoustic representation in Experiment 1) were not included in this study. The possibility of acoustic representation influencing intralist probe difficulty should have been constant across list conditions. An imbalance in same vs. different negative probe frequency $(2: 1)$ would not have provided a reasonable test of list homogeneity effects.

Procedure. Word lists were presented at a rate of 2 pairs/sec. Twelve subjects always received a homogeneous attended list (AA and $\mathrm{AX}$ ), the other subjects, a mixed category attended list (XA and $\mathrm{XX}$ lists). With 10 trials per negative probe type per list condition, positive and negative trials were randomized 
within two blocks for each group. Counterbalancing for attended ear (right or left) and positive-negative response fingers was carried out between subjects and remained constant for the whole $(40-\mathrm{min})$ session. Practice trials were given to criterion, and rest periods were provided between blocks.

\section{Results and Discussion}

Mean correct RTs and error rates for positive, negative intralist, and negative extralist probes following $\mathrm{AA}, \mathrm{AX}, \mathrm{XA}$, and $\mathrm{XX}$ lists are shown in Figure 2.

An analysis of variance with the factors of attended list homogeneity (two), unattended list homogeneity (two), and probe type (three) was performed on mean correct response times. The only significant main effect was that of probe type $[F(2,22)=24.33, p<.001]$, reflecting longer RTs for intralist than extralist probes, which in turn were responded to slower than positive probes. Only the three-way interaction was significant $[F(2,22)=7.36, p<.01]$. Decomposition showed that variation in the homogeneity of either list had no effect on positive or extralist probes, whereas the longest RTs for intralist probes were found with $\mathrm{AX}$ lists. If responises to intralist probes were longer following $A A$ rather than $\mathrm{AX}$ lists, and XA compared to XX lists, this would indicate that categorization of unattended items had occurred. No difference in RT was found between XA and XX, and, in contrast, probe $\mathrm{RT}$ was longer after $\mathrm{AX}$ than AA lists. No difference would indicate no categorization of unattended items. The generality of the unexpected increase in RT following AX lists was examined in a post hoc analysis of serial position. This intralist probe effect was attributable to very long RTs for 5 out of 12 subjects to probes that

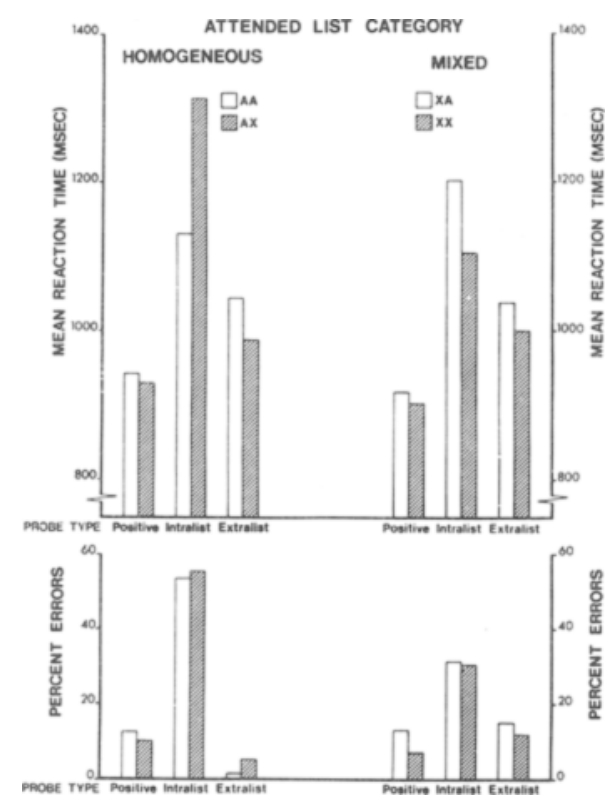

Figure 2. Mean correct RTs and error rates for negative (intralist and extralist) probes following homogeneous attended lists paired with unattended homogeneous (AA) or mixed categories $(\mathrm{AX})$ and mixed category attended lists paired with unattended homogeneous (XA) or mixed categories (XX). were initial items on the unattended list. Although the attended ear was cued, it is possible that with the onset of dichotic inputs there may need to be some reorientation to the appropriate ear. Some subjects apparently found this difficult and sampled the initial unattended item. This item may have been involuntarily incorporated in to the positive set. Intralist probe RT and error rates were similar at each serial position probed across list conditions; however, a marked recency effect was found with all lists for positive probes.

The error analysis (see Figure 2) showed a significant main effect of probe type $[F(2,22)=109.86, p<.001]$, and an interaction of Attended List Homogeneity by Probe Type $[F(2,22)=19.72, p<.001]$. With a single category on the attended list (AA and $\mathrm{AX}$ ), errors to intralist probes were higher $(54.7 \%)$ than mixed attended lists (XA and XX; 31.0\%). For the category manipulation on the unattended list to have had an effect, the interaction of Probe Type by Unattended List Homogeneity should have been significant. However, it was not $[F(2,22)<1]$. Neither was the three-way interaction significant $[F(2,22)=3.14, p>.05]$. An examination of errors to different probe types independently showed that there were slightly fewer errors following XX lists. However, errors for extralist probes increased by $14.4 \%$ when the attended list was mixed rather than homogeneous (see Figure 2). The results show that the category manipulation had a much greater effect when this was carried out on the attended rather than the unattended list.

The category relationship between list words was constructed to permit semantic facilitation by either the attended or unattended list. However, even with this possibility, there was no evidence to suggest that unattended processing influenced within-categories discrimination when a probe word was of the same category as attended list words. No decrease in RT or errors was found for intralist probes (of the same category as the attended list) when the attended list was homogeneous (AA vs. AX). Only one unattended item on the list produced as much or more difficulty as six unattended items. Furthermore, responses to $\mathrm{XA}$ and $\mathrm{XX}$ lists did not differ either.

\section{EXPERIMENT 3}

To further examine the level of processing of attended and unattended items, focused and divided attention strategies were compared using completely heterogeneous lists. A higher level of processing was expected for attended than unattended items, and in focused rather than divided attention. Semantic and phonemic processing were investigated by comparing performance on negative probes. Semantic processing would be shown by a greater response difficulty to probe words that were semantic associates of attended or unattended list words than to nonassociates not occurring on either list. Phonemic processing (i.e., 
categorical perception) would be indicated by more difficulty in response to probe words that differed in only one phoneme from a word presented on a list than in response to phonemically dissimilar words. Thus, it was expected that the relative levels of response difficulty would depend on recognition of some similarity in features between a probe word and a list item; the specificity of difficulty (phonemic or semantic) would, therefore, reflect the level at which dichotic lists were processed.

\section{Method}

Subjects. The subjects were 32 right-handed undergraduates. No subject had a known hearing defect or had taken part in the previous experiments. Subjects were randomly allocated to either a focused attention or divided attention condition.

Apparatus. Tape preparation and stimulus presentation were basically the same as in Experiment 1, with word lists recorded on two channels, prelist tones instead of digits on another channel, and postlist tones on the fourth channel. An initial tape was constructed with a total of 360 trials, 120 trials for each of three dichotic list lengths (one, two, or four pairs) and equal numbers of positive and negative probes drawn from either channel. Two master tapes were then prepared from this tape, one for the focused attention condition and one for the divided attention. The focused attention tape was derived by randomly transposing 50 of the 60 positive trials per list length initially recorded on Channel 2 onto Channel 1, and at the same time eliminating 10 of the 20 extralist unrelated probe trials. The divided attention tape was prepared by eliminating five positive trials per channel for each list length. These tapes gave a ratio of $45: 55$ positive-to-negative trials. All word lists of the focused attention tape were preceded by prelist tones on the attended ear(s) and postlist tones on both ears by selectively mixing Channels 3 and 4 with the attended and unattended word lists.

Stimulus materials. Dichotic lists with set sizes of one, two, or four pairs of monosyllabic nouns were selected for equivalent word frequencies (Howes, 1966; Thorndike \& Lorge, 1944), phonemic length (Landauer \& Streeter, 1973), and low semantic association values (Palermo \& Jenkins, 1964; Postman \& Keppel, 1970 ). Words on paired lists shared no more than one phoneme in the same position.

The definition of probe words is illustrated in Table 3. Positive probes were items of the attended list in focused attention ( 50 trials per set size) and of either list in divided attention (25 trials per channel per set size). Negative probes in divided attention were (1) phonemic, (2) semantic, or (3) unrelated probes. Phonemic probes were low associates of all list items on a given trial and differed from the probed item in only one phoneme, the change in phoneme occurring with either the initial or final consonant, or the vowel. Semantic probes were phonemically unrelated to all list items per trial but were of high associative value with one item. Channels were probed equally often with phonemic and semantic probes (10 trials per channel per probe) and over Serial Positions 1, 2, and 4 in the set size of four pairs. Unrelated probes were phonemically and semantically unrelated to items on both dichotic lists, and therefore served as a control probe measure for both phonemic and semantic probes.

Focused attention contained the same phonemic and semantic probes for each channel as in divided attention but were designated as attended or unattended list (negative) probes. There were 10 trials with unrelated probes, and the balance of trials was made up with intralist probes, identical to items on he unattended list. Trials were randomly distributed within slocks by set size with 110 trials per block.

Procedure. As in the previous experiments, response finger
Table 3

Examples of Dichotic Lists in Focused and Divided Attention Conditions and the Relationship of Various Probe Words to the Respective Lists

\begin{tabular}{|c|c|c|c|c|}
\hline \multicolumn{3}{|c|}{ Channel 1} & \multicolumn{2}{|c|}{ Channel 2} \\
\hline \multicolumn{3}{|c|}{$\begin{array}{l}\text { farm } \\
\text { knot } \\
\text { king } \\
\text { pipe }\end{array}$} & \multicolumn{2}{|c|}{$\begin{array}{l}\text { mouse } \\
\text { soap } \\
\text { park } \\
\text { glue }\end{array}$} \\
\hline \multirow{2}{*}{$\begin{array}{l}\text { Probe } \\
\text { Words }\end{array}$} & \multicolumn{2}{|c|}{ Correct Response } & \multicolumn{2}{|c|}{ Probe Classification } \\
\hline & Focused & Divided & Focused & Divided \\
\hline $\begin{array}{l}\text { farm } \\
\text { soap }\end{array}$ & $\begin{array}{l}\text { positive } \\
\text { negative* }\end{array}$ & positive & identical & identical \\
\hline $\begin{array}{l}\text { knob } \\
\text { part }\end{array}$ & negative & negative & phonemic & phonemic \\
\hline $\begin{array}{l}\text { queen } \\
\text { rat }\end{array}$ & negative & negative & semantic & semantic \\
\hline lime & negative & negative & unrelated & unrelated \\
\hline
\end{tabular}

Note-Channel $1=$ focused attended, divided attended; Channel 2 = focused unattended, divided attended.

*In the focused condition, only the attended items constituted the positive set.

and order of blocked presentations were counterbalanced between subjects. Of the 16 subjects asked to attend equally to both lists, 8 subjects received Channel 1 to the right ear; the remainder had the same channel to the left ear. In focused attention, half of the subjects attended to the right ear and half to the left ear. Practice lists sampled all probe types and preceded each set size. Rest periods were given after every 55 trials during the 90-min session.

\section{Results and Discussion}

Probe words (positive or negative) were classified according to whether they were identical (intralist) or related (phonemic or semantic) to list words on either Channel 1 or 2 . In both attention conditions, Channel 1 was the attended input. Channel 2 was also an attended input in the divided attention condition, whereas it was the irrelevant input in the focused condition. Unrelated probes could not be classified in terms of channel of relation, since they were unrelated to all items on both lists.

The mean RTs for correct responses are shown in Figure 3. An ANOVA was performed on mean correct RTs with the factors of attention condition (focused vs. divided), set size (one, two, or four pairs), channel (1 vs. 2), and probe type (intralist, phonemic, or semantic). Response latency increased with set size $[F(2,30)=6.15, \quad p<.05]$ and was slower after phonemic probes $[F(2,30)=45.08, p<.001]$. The interaction of Attention by Set Size by Probe Type was significant $[F(4,60)=3.81, p<.001]$. RT for intralist and phonemic probes increased to a greater extent with set size in the focused than in the divided conditions. Probe type interacted with attention condition $[F(2,30)=8.03, p<.01]$ as well as channel $[F(2,30)=47.28, p<.001]$. The three-way interaction 


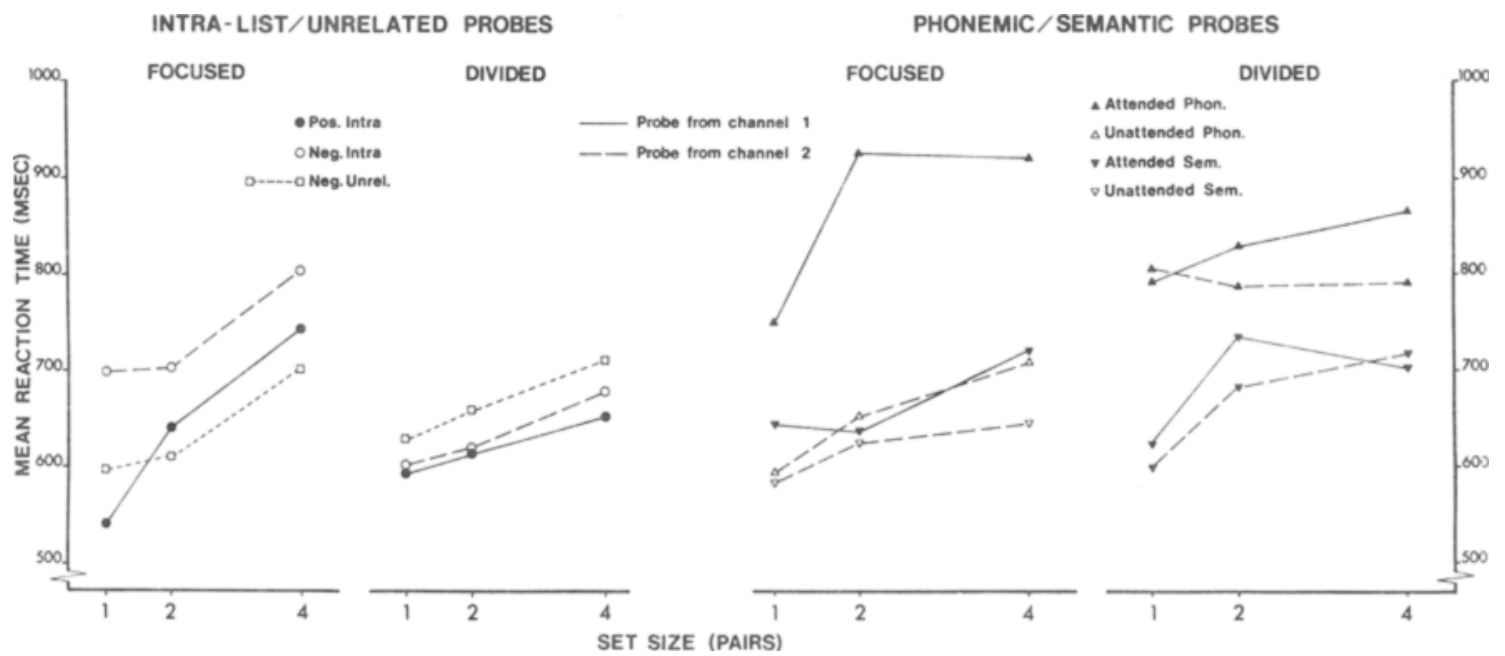

Figure 3. Mean correct RTs for positive and various negative probes with focused and divided attention. Probes were identical to a list item (positive and negative intralist), phonemically or semantically related to a word on Channel 1 or 2 , or unrelated to words on either list.

of Probe Type by Attention Condition by Channel was significant $[F(2,30)=24.94, p<.001]$. However, the four-way interaction was not significant $[F(4,60)=1.64$, $\mathrm{p}>$.05].

Summing across set size, comparisons showed that RT to semantic probes did not differ in terms of the channel to which that probe was related, in either the focused $($ mean $=645 \mathrm{msec})$ or divided $($ mean $=680 \mathrm{msec})$ condition. Positive probes were responded to similarly in the focused condition (mean $=641 \mathrm{msec}$ ) and either channel in the divided condition (mean $=620$, $635 \mathrm{msec}$ ). The negative intralist probe from the attended channel in focused attention was responded to more slowly than positive probes in either attention condition. This negative probe also produced longer latencies (mean $=736 \mathrm{msec}$ ) than the phonemic probe of the unattended list (mean $=655 \mathrm{msec}$ ). However, phonemic probe RT of the focused attended list (mean $=866 \mathrm{msec})$ did not differ from the same attended list in divided attention (mean $=832 \mathrm{msec}$ ), nor did the latter differ from the other divided attended list (mean $=797 \mathrm{msec}$ ).

In view of the large difference in RT between phonemic and semantic probes, the generality of phonemic probe effects was examined further. Mean correct RTs for phonemic probes were compared with those for unrelated probes using Clark's (1973) min $F^{\prime}$ test. The factors for both subject and word analyses were attention condition (two), set size (two), and probe type (phonemic probe of Channel 1, Channel 2, or unrelated probe). There were twice as many unrelated probes in divided than in focused attention. Therefore, only the RTs for unrelated probes presented in both conditions were used in this analysis. The set-size effect that had been significant with subjects was not significant with words $\left[\min F^{\prime}(1,101)=2.22, p>05\right]$. Slower responses occurred with phonemic probes of items on Channel 1 than with phonemic probes of Channel 2 or unrelated probes $\left[\min \mathrm{F}^{\prime}(1,107)=24.12\right.$, $\mathrm{p}<.001]$. The significant interaction of attention condition with probe type $\left[\min \mathrm{F}^{\prime}(1,105)=5.15\right.$, $\mathrm{p}<.05]$ showed that rejecting phonemic probes of the unattended list was no more difficult than rejecting unrelated probes. However, probes that were phonemically related to the attended inputs (Channel 1 in focused, both channels in divided) were more difficult to reject than unrelated probes.

Errors. Mean errors (shown in Table 4) were analyzed with the factors of attention condition (two), set size (three), channel of probe (two), and probe type (three: intralist, phonemic, semantic). All main effects were significant $(p<.001)$, as were all two-way interactions except Set Size by Channel $[F(2,30)=1.48, p>.05]$. Since the four-way interaction was not significant $[F(4,60)=2.33, p>.05]$, the results will be considered in terms of the significant three-way interactions. The interaction of Attention by Set Size by Channel $[F(2,30)=12.64, \quad p<.001]$ showed that errors increased with set size for probes of both attended channels in divided attention, whereas errors increased with set size on only the attended channel in focused attention; that is, there was no effect of set size on errors to probes related to the unattended input. The interaction of Set Size by Channel by Probe Type $[F(4,60)=13.01, p<.001]$ indicated that error rates increased with set size more for phonemic probes of Channel 1 (attended in both attention conditions) than Channel 2, but not for in tralist or semantic probes. The only other significant interaction, Attention by Channel by Probe Type $[F(2,30)=12.26, p<.001]$, reflected the difference in error rates between channels with only intralist and phonemic probes in focused attention, whereas in divided attention there was no channel difference. A min $F^{\prime}$ test on phonemic vs. 
Table 4

Mean Percent Errors for Each Channel in Focused and Divided Attention According to Set Size and Probe Type

\begin{tabular}{|c|c|c|c|c|c|c|c|c|c|c|c|c|c|}
\hline \multirow{3}{*}{$\begin{array}{l}\text { Probe } \\
\text { Type }\end{array}$} & \multirow{3}{*}{$\begin{array}{c}\text { Chan- } \\
\text { nel }\end{array}$} & \multicolumn{4}{|c|}{ Set Size 1} & \multicolumn{4}{|c|}{ Set Size 2} & \multicolumn{4}{|c|}{ Set Size 4} \\
\hline & & \multicolumn{2}{|c|}{ Focused } & \multicolumn{2}{|c|}{ Divided } & \multicolumn{2}{|c|}{ Focused } & \multicolumn{2}{|c|}{ Divided } & \multicolumn{2}{|c|}{ Focused } & \multicolumn{2}{|c|}{ Divided } \\
\hline & & Mean & SE & Mean & SE & Mean & $\mathrm{SE}$ & Mean & $\mathrm{SE}$ & Mean & $\mathrm{SE}$ & Mean & SE \\
\hline Intralist & $\begin{array}{l}1 \\
2 *\end{array}$ & $\begin{array}{l}7.9 \\
1.9\end{array}$ & $\begin{array}{l}1.3 \\
1.4\end{array}$ & $\begin{array}{r}6.5 \\
11.0\end{array}$ & $\begin{array}{l}1.3 \\
2.2\end{array}$ & $\begin{array}{l}4.7 \\
2.8\end{array}$ & $\begin{array}{l}1.4 \\
1.8\end{array}$ & $\begin{array}{l}18.5 \\
11.9\end{array}$ & $\begin{array}{l}2.7 \\
2.2\end{array}$ & $\begin{array}{r}9.8 \\
10.3\end{array}$ & $\begin{array}{l}2.0 \\
2.2\end{array}$ & $\begin{array}{l}17.6 \\
27.1\end{array}$ & $\begin{array}{l}3.7 \\
3.8\end{array}$ \\
\hline Phonemic & $\begin{array}{l}1 \\
2\end{array}$ & $\begin{array}{r}21.3 \\
.6\end{array}$ & $\begin{array}{r}6.3 \\
.6\end{array}$ & $\begin{array}{l}30.2 \\
26.3\end{array}$ & $\begin{array}{l}4.0 \\
5.2\end{array}$ & $\begin{array}{r}15.0 \\
3.1\end{array}$ & $\begin{array}{l}5.1 \\
1.5\end{array}$ & $\begin{array}{l}26.1 \\
32.3\end{array}$ & $\begin{array}{l}3.7 \\
4.7\end{array}$ & $\begin{array}{r}42.6 \\
2.1\end{array}$ & $\begin{array}{l}5.3 \\
1.2\end{array}$ & $\begin{array}{l}49.0 \\
45.3\end{array}$ & $\begin{array}{l}4.5 \\
4.2\end{array}$ \\
\hline Semantic & $\begin{array}{l}1 \\
2\end{array}$ & $\begin{array}{l}3.1 \\
1.3\end{array}$ & $\begin{array}{l}1.2 \\
1.3\end{array}$ & $\begin{array}{r}.6 \\
1.9\end{array}$ & $\begin{array}{r}.6 \\
1.4\end{array}$ & $\begin{array}{r}.6 \\
0.0\end{array}$ & $\begin{array}{r}.6 \\
0.0\end{array}$ & $\begin{array}{l}5.1 \\
4.4\end{array}$ & $\begin{array}{l}1.8 \\
1.6\end{array}$ & $\begin{array}{l}2.1 \\
3.6\end{array}$ & $\begin{array}{l}1.2 \\
1.1\end{array}$ & $\begin{array}{r}5.8 \\
12.1\end{array}$ & $\begin{array}{l}1.8 \\
2.4\end{array}$ \\
\hline Unrelated & & .6 & .6 & .3 & 1.3 & .6 & .6 & 1.0 & .5 & 4.3 & 1.2 & 9.4 & 2.1 \\
\hline
\end{tabular}

*Intralist probes on Channel 2 were positive in divided attention but negative in focused attention.

unrelated probes supported the difference between attended and unattended phonemic probe errors $\left[\min \mathrm{F}^{\prime}(1,42)=8.32, \mathrm{p}<.01\right]$.

Since unrelated and semantic probes were rejected with equal ease, it appears either (1) that semantic associates with heterogeneous lists may not have been sufficiently sensitive to measure the degree of semantic processing, or (2) that the level of processing was mostly phonemic. If semantic attributes of list items had been encoded, then this information should have facilitated the rejection of phonemic probes, and more so in focused than in divided attention. Some support for the effect of attention strategy on the accuracy of phonemic probe rejection can be seen in Table 4. The same phonemic probes of the attended list (Channel 1) were responded to with fewer errors in each set size (from 7\% to $11 \%$ ) in focused than in divided attention. However, phonemic encoding may also have been better in focused than in divided attention. A separate analysis of intralist vs. unrelated probes according to attention condition, channel, and set size gave only a main effect of attention condition $[F(1,30)=4.18, p<.05]$, reflecting higher error rates in divided than in focused attention.

The effect of attended list phonemic probes clearly suggests that a decision difficulty was produced and an incorrect response initiated on the basis of a phonemic match of the probe word to an item in memory, which shared two phonemes with the probe. This difficulty was not found with phonemic probes of the unattended ist. Yet, intralist probes from the unattended list produced a decision difficulty that remained constant over set size. If unattended items had been encoded phonemically, they should have presented a similar level of difficulty as negative intralist probes.

The level of encoding of attended vs. unattended tems was further examined with linear-regression inalyses. The steeper slope for the positive probe RT unction in focused attention (64.54 msec) compared with the slope for the negative intralist (unattended) robe $(37.56 \mathrm{msec})$ suggests that this negative probe nay have been rejected following a preliminary scan for tem relevancy. The difference between the positive and negative intralist slopes $(27 \mathrm{msec})$ suggests that a second scan was initiated at a rate very similar to that for divided attention positive probes $(25.29 \mathrm{msec})$. However, if an initial scan is sufficient for a negative response criterion to be reached (Heussman \& Woocher, 1976 ), then the similarity in slope between the negative intralist and focused unrelated probe $(35.16 \mathrm{msec})$ cannot be explained. Clearly, any preliminary scan must have also taken into account the dissimilarity of the unrelated probe to the positive set of attended items. The slope for the phonemic probe of the unattended list $(37.19 \mathrm{msec})$ was almost identical to that for the negative intralist probe. The difference in intercepts (intralist, $649 \mathrm{msec}$; phonemic, $568 \mathrm{msec}$ ) reflects the greater decision time to reject the intralist than the phonemic probes related to unattended items, which were at the level of difficulty of unrelated probes (intercept, $555 \mathrm{msec}$ ). Therefore, unattended words could not have been phonemically analyzed.

The syllable is generally considered to be the "basic acoustic unit of speech perception" (Studdert-Kennedy, 1976, p. 153). Since the words in all lists were monosyllabic and generally low frequency, phonemic encoding may have required attention. Infrequent words differ phonemically from common words (Landauer \& Streeter, 1973). Furthermore, even when the memory span was not exceeded, phonemic encoding was more efficient with focusing on one input than attempting to allocate attention between pairs of words. Thus, the better processing of focused attended words was gained at the expense of unattended processing.

\section{GENERAL DISCUSSION}

Experiment 1 replicated the main finding of Smith and Groen (1974). Negative intralist (unattended item) probes were more difficult to reject when dichotic lists shared rather than differed in category. This difficulty was not reduced by precuing the attended list. Extralist probes matching the attended list category were also more difficult to reject than nonmatching probes. However, this category effect was only evident 
with probes following cued lists, suggesting that perceptual selection promoted more efficient categorizing of attended but not unattended words. When the probe matched the category on the attended list and had been an unattended item, it was more likely to be responded to in error.

Experiment 2 showed that the difficulty in response to intralist probes did not vary with the homogeneity of category on the unattended list. The number of categories on an unattended list and the number of exemplars between lists matching the attended list category did not consistently affect RT or errors with the appropriate probes. However, both factors contributed to response difficulty with attended list homogeneity.

Experiment 3 found no evidence for response difficulty of semantic origin with either attended or unattended list probes. However, both errors and RT indicated that phonemic analysis of attended words had taken place. Positive intralist (attended items) and negative phonemic probes of the attended list were responded to more accurately in focused than in divided attention. Negative intralist probes showed more decision difficulty than phonemic probes of the unattended list, suggesting that a precategorical acoustic trace can be sufficient to produce a response difficulty.

Probe words that shared a feature with items of the positive set were more difficult to reject than probes that did not have this feature. This has been shown both at a phonemic level (Foss \& Dowell, 1971) and at the level of conceptual representation (Dumas, Gross, \& Checkosky, 1972; Ellis \& Chase, 1971; Lively \& Sanford, 1972; Smith \& Groen, 1974). Intralist probe difficulty following categorizable dichotic lists appears to be a special case of the probe similarity effect. The category on the unattended list appears to be important only insofar as it defines the category relationship between an intralist probe and the category of the positive set. Same category lists and thus category matching intralist probes seem to be sufficient to produce a considerable difficulty in correct rejection of the intralist probe. Extralist probes also matching the attended list category produce a similar difficulty. However, extralist probes cannot be matched to an item representation in recent memory, whereas any additional difficulty, and higher error rates, with in tralist probes can be attributed to such an item feature match.

In Experiment 1, there was some evidence for a decrement in the efficiency of attended list processing with noncued lists. Intralist probe difficulty was stable irrespective of perceptual selection. However, when category information pertaining to the attended list appeared to be lacking, response difficulty with intralist probes cannot be accounted for on a semantic basis. As found in Experiment 3, and by Byrnes (1976), a probe from an unattended list can produce response difficulty. Furthermore, the variables that should influence search and decision time (Experiment 2) showed no effect of unattended item processing. It is possible that the dichotic words were adequately tagged by ear of arrival, and would therefore not influence response. Then, intralist probe errors should have been lower in the categorizing experiments.

Lyons (1974) found that probes rhyming with the most recent unattended items on 10-word lists were more likely to be responded to in error than semantically related probes. This finding suggests phonemic analysis of the unattended input, contrary to the present results. However, Lyons' (1974) subjects were given $8 \mathrm{sec}$ to respond. The acoustic similarity of the probe to an item in recent memory could have precipitated phonemic analysis during the response interval, rather than during list presentation.

Differential processing of verbal material (e.g., phonemic vs. semantic) has been found even with tasks not involving perceptual selection (Goldstein, 1975; Treisman \& Squire, 1974). It is not surprising, then, to find evidence for semantic analysis when the subject can conceptualize a category as being representative of an attended list, thereby facilitating task performance. An awareness of decision difficulty when presented with phonemic probes (varying in the location of phonemic dissimilarity within an item) may well have increased the probability of fine phonemic discrimination during list presentation. Unattended words may be semantically analyzed, for example, under conditions of uncertainty in perception (e.g., when the relevant message is ambiguous). However, when task performance cannot benefit from unattended processing, categorical perception at either a phonemic or semantic level appears to be confined to the attended message. Pre-vs. postperceptual selection may need to be considered in terms of the conditions conducive to task performance.

\section{REFERENCES}

Battig, W. F., \& Montague, W. E. Category norms for verbal items in 56 categories: A replication and extension of the Connecticut category norms. Journal of Experimental Psychology Monograph, 1969, 80(3, Part 2).

BRYDEN, M. P. Attentional strategies and short-term memory in dichotic listening. Cognitive Psychology, 1971, 2, 99-116.

Byrnes, D. L. Memory search of dichotically presented lists of digits. Bulletin of the Psychonomic Society, 1976, 8, 185-187.

Clark, H. H. The language-as-a-fixed-effect fallacy: A critique of language statistics in psychological research. Journal of Verbal Learning and Verbal Behavior, 1973, 12, 335-339.

Dallas, M., \& Merukle, P. M. Semantic processing of nonattended visual information. Canadian Journal of Psychology, 1976, 30, 15.21.

Davis, J. C., \& SмIтh, M. D. Memory for unattended input. Journal of Experimental Psychology, 1972, 96, 380-388.

Dumas, J., Gross, E., \& Checkosky, S. Effects of attribute probability in a memory search task. Journal of Experimental Psychology, 1972, 93, 327-332.

Ellis, S. H., \& Chase, W. G. Parallel processing in item recognition. Perception \& Psychophysics, 1971, 10, 379.384.

Foss, D. J., \& Dowell, B. E. High-speed memory retrieval with auditorily presented stimuli. Perception \& Psychophysics, $1971,9,465-468$.

Glucksberg, S., \& Cowen, G. N., JR. Memory for non-attended 
auditory material. Cognitive Psychology, 1970, 1, 149-156. GoldsteIN, E. F. Selective phonemic and semantic coding in short-term recall. Memory \& Cognition, 1975, 3, 619-626.

HeNLEy, S. H. A. Responses to homophones as a function of cue words on the unattended channel. British Journal of Psychology, 1976, 67, 559-567.

Heusmann, L. R., \& Woocher, F. D. Probe similarity and recognition of set membership: A parallel-processing serialfeature-matching model. Cognitive Psychology, 1976, 8, 124-162.

Howes, D. A word count of spoken English. Journal of Verbal Learning and Verbal Behavior, 1966, 5, 572-604.

Kadesh, I., Riese, M., \& Anisfeld, M. Dichotic listening in the study of semantic relations. Journal of Verbal Learning and Verbal Behavior, 1976, 15, 213-225.

KLAPP, S. T., \& LEE, P. Time-of-occurrence cues for "unattended" auditory material. Journal of Experimental Psychology, 1974, $102,176-177$.

LACKNER, J. R., \& GARRETT, M. F. Resolving ambiguity: Effects of biasing context in the unattended ear. Cognition, $1973,1,359-372$.

LANDaUer, T. K., \& Streeter, L. A. Structural differences between common and rare words: Failure of equivalence assumptions for theories of word recognition. Joumal of Verbal Learning and Verbal Behavior, 1973, 12, 119.131.

LEwIs, J. L. Semantic processing of unattended messages using dichotic listening. Journal of Experimental Psychology, 1970, 85, 225-228.

LIVELY, B. L., \& SANFORD, B. J. The use of category information in a memory-search task. Journal of Experimental Psychology. $1972,93,379-385$.

Lyons, J. L. The encoding of ignored information. Memory \& Cognition, 1974, 2, 161-168.

NaUs, M. J. Memory search of categorized lists: A consideration of alternative self-terminating search strategies. Journal of Experimental Psychology, 1974, 102, 992-1000.

Palermo, D. S., \& Jenkins, J. J. Word association norms: Grade school through college. Minneapolis: University of Minnesota Press, 1964.

Posner, M. 1., \& SNYDER, C. R. R. Attention and cognitive control. In R. L. Solso (Ed.), Information processing and cognition. Hillsdale, N.J: Erlbaum, 1975.
Postman, L. J., \& KePpel, G. (Eds.). Norms of word association. New York: Academic Press, 1970.

Shiffrin, R. M., \& Schneider, W. Controlled and automatic human information processing: II Perceptual learning, automatic attending and a general theory. Psychological Review, $1977,84,127-190$.

SMith, M. C., \& ABEL, S. M. Memory search: When does semantic analysis occur? Perception \& Psychophysics, 1973, 13, 233-237.

Smith, M. C., \& BurRows, D. Memory scanning: Effect of unattended input. Journal of Experimental Psychology, 1974, 102, 722-725.

SMITH, M. C., \& Groen, M. Evidence for semantic analysis of unattended verbal items. Journal of Experimental Psychology, $1974,102,595-603$.

Studdert-Kennedy, M. Speech perception. In N. J. Lass (Ed.), Contemporary issues in experimental phonetics. New York: Academic Press, 1976.

THORNDIKE, V. L., \& LORGE, L. The teacher's word book of 30,000 words. New York: Bureau of Publications, Teacher's College, Columbia University, 1944.

Treisman, A. Monitoring and storage of irrelevant messages in selective attention. Joumal of Verbal Learning and Verbal Behavior, 1964, 3, 449-459.

Treisman, A., \& Squire, R. Listening to speech at two levels at once. Quarterly Journal of Experimental Psychology, 1974, 26, 82-97.

Treisman, A., Souire, R., \& Green, J. Semantic processing in dichotic listening? A replication. Memory \& Cognition, 1974, 2, 641-646.

UNDERWOOD, G. Semantic interference from unattended printed words. British Joumal of Psychology, 1976, 67, 327-338.

UNDERWOOD, G. Contextual facilitation from attended and unattended messages. Journal of Verbal Leaming and Verbal Behavior, 1977, 16, 99-106.

(Received for publication June 23, 1978; revision accepted December $12,1978$. 